Résumés des conférences et travaux

\title{
Le chef des eunuques du Harem impérial ottoman
}

Origines, influence, représentations

Jane Hathaway

\section{OpenEdition \\ Journals}

Édition électronique

URL : https://journals.openedition.org/ashp/646

DOI : 10.4000/ashp.646

ISSN : 1969-6310

Éditeur

Publications de l'École Pratique des Hautes Études

Édition imprimée

Date de publication : 1 octobre 2009

Pagination : 75-77

ISSN : 0766-0677

Référence électronique

Jane Hathaway, "Le chef des eunuques du Harem impérial ottoman », Annuaire de l'École pratique des hautes études (EPHE), Section des sciences historiques et philologiques [En ligne], 140 | 2009, mis en ligne le 07 octobre 2009, consulté le 06 juillet 2021. URL : http://journals.openedition.org/ashp/646 DOI : https://doi.org/10.4000/ashp.646 


\title{
LE CHEF DES EUNUQUES DU HAREM IMPÉRIAL OTTOMAN
}

\author{
ORIGINES, INFLUENCE, REPRÉSENTATIONS
}

\author{
Conférences de $\mathrm{M}^{\text {me }}$ Jane Hatha Way, \\ professeur à l'Ohio State University (États-Unis), \\ directeur d'études invité
}

J'ai présenté, dans le cadre de la direction d'études de M. Nicolas Vatin, quatre conférences sur le thème « Le chef des eunuques du Harem impérial ottoman. Origines, influence, représentations », les jeudi 29 mai et 5 juin, le mardi 10 juin et le jeudi 12 juin 2008 .

Ces conférences étaient fondées sur mes recherches en cours sur l'office de chef des eunuques du Harem (darüssade ăgası ou klzlar ağası) dans l'Empire ottoman et sur l'évolution de cette fonction de ses débuts à la fin du XVI ${ }^{e}$ siècle jusqu'à sa dissolution à la fin de l'Empire ottoman à la suite de la première guerre mondiale. Le sujet a été abordé dans une approche thématique : origines de l'institution; principaux vecteurs de l'influence du chef des eunuques; son impact sur la vie religieuse et intellectuelle ottomane; son héritage. Ce fut aussi l'occasion de comparaisons avec les eunuques dans d'autres sociétés.

\section{Les eunuques du Harem : la question des origines}

Dans l'Empire ottoman comme dans la plupart des sociétés islamiques, les eunuques étaient pris parmi l'élite des esclaves châtrés au moment de leur asservissement et convertis à l'islam. L'émasculation étant contraire à la loi islamique, beaucoup étaient châtrés à la périphérie du territoire ottoman. Bien que les eunuques ottomans fussent pour la plupart de sexe masculin, on considérait que certaines de leurs particularités et fonctions - indépendamment de leur évidente différence physique - les distinguaient des mâles non châtrés.

En employant des eunuques africains comme gardiens du harem du souverain, les Ottomans suivaient une tradition remontant au moins au califat abbaside. Mais quand en 1541 le Harem ottoman déménagea du « Vieux Palais » pour celui de Topkap1 sur l'ordre de l'influente épouse de Soliman le Magnifique, les gardiens africains du Harem du Vieux Palais se trouvèrent confrontés aux eunuques largement balkaniques, pour la plupart issus du devşirme ${ }^{1}$, qui gardaient la Babüssaade, c'est à dire le seuil de la chambre des audiences du sultan. Cette dichotomie ethnico-raciale se perpétua après l'abandon du devşirme au XVII ${ }^{\mathrm{e}}$ siècle, les eunuques de la Babüssaade provenant désormais du Caucase. Cette bipolarisation et la rivalité occasionnelle entre les

1. La « récolte », à intervalles plus ou moins réguliers, de jeunes sujets non musulmans de l'Empire. islamisés et employés comme « esclaves » (kul) du sultan. 
deux corps d'eunuques est un des traits les plus surprenants des institutions palatiales, qu'on ne peut pas expliquer par un racisme du type de ceux que nous connaissons de nos jours.

L'office de Darüssaade ağası fut officiellement créé en 1582, quand Murâd III retira la supervision des fondations pieuses des villes saintes de La Mecque et Médine (Haremeyn Evkafi) au chef de eunuques du seuil (le Babüssaade ağası) pour la confier au plus élevé en grade des eunuques du Harem, Habeşî Mehmed Ağa. Ce geste ne faisait en réalité que confirmer l'influence considérable qu'avait déjà acquise Habeşî Mehmed Ağa.

\section{Les voies de l'influence du chef des eunuques du Harem : le palais et les provinces}

À l'intérieur même du palais de Topkap1, le chef des eunuques du Harem commença à exercer une forte influence sur la formation du sultan sous le règne d'Ahmed $\mathrm{I}^{\text {er }}$ (1603-1617), quand les princes ne furent plus envoyés gouverner des provinces anatoliennes pour apprendre l'art de gouverner et quand les nouveaux sultans n'ordonnèrent plus systématiquement l'exécution de leurs frères. En conséquence, de nombreux princes étaient maintenant entièrement élevés au Harem, où le chef des eunuques supervisait leur première éducation. De ce fait, le chef des eunuques et la mère du sultan acquirent une influence prédominante dans la formation du caractère et de la vision du monde du souverain. Une fois celui-ci monté sur le trône, le Babüssade ağası pouvait aisément influer sur ses décisions et les nominations. Les longues carrières de Hac1 Mustafa Ağa (en fonction de 1605 à 1619 et en 1623-1624) et Hacı Beşir Ağa (en fonction de 1717 à 1746) fournissent de bons exemples de ce type d'influence.

Dans l'exercice de ses fonctions de surintendant des fondations pieuses des deux Villes Saintes (Haremeyn evkafi), le chef des eunuques entretenait un réseau de clients dans toutes les provinces ottomanes. Des territoires agricoles et d'autres propriétés étaient légués aux vakf à travers tout l'empire et de féroces compétitions pouvaient apparaître entre les notables des provinces pour les fermes fiscales ou les propriétés constituées en fondation. C'était particulièrement vrai en Égypte, où de nombreux villages fournissaient des grains aux Villes Saintes. Ce n'est probablement pas une coïncidence si, à partir du milieu du XVII ${ }^{\mathrm{e}}$ siècle, les chef des eunuques et les autres eunuques du Harem démis de leurs fonctions étaient systématiquement exilés au Caire. Le Caire accueillit ainsi nombre d'anciens eunuques du Harem qui entretinrent des liens

étroits avec les notables militaires et administratifs d'Égypte et devinrent vraisemblablement eux-mêmes des notables locaux.

\section{L'influence du chef des eunuques sur la vie religieuse et intellectuelle ottomane}

L'influence du chef des eunuques du Harem dans les domaines religieux et culturel revêt trois aspects.

En premier lieu, il semble avoir joué un rôle majeur dans la commande de manuscrits illustrés et de bâtiments religieux. C'est ainsi qu'on attribue à Habeşi Mehmed Ağa 
la commande du magnifique Sürname préparé pour Murad III, tandis que Hacı Mustafa Ağa joua un rôle majeur dans la construction de la fameuse mosquée Bleue.

Deuxièmement, par ses propres fondations pieuses le chef des eunuques du Harem renforçait l'école juridique (mezhep) hanéfite - l'école officielle ottomane - et l'attachement ottoman aux ordres soufis « de la grande tradition ». On notera particulièrement à ce sujet les bibliothèques, principalement constituées d'ouvrages de théologie et de droit hanéfite, que nombre de chef des eunuques constituèrent en fondations pieuses à Istanbul et en province. Entre autres avantages, cette pratique renforçait la présence hanéfite dans les provinces arabes, où le mezhep hanéfite était souvent en compétition avec les autres écoles.

Enfin l'un des sites les plus sacrés de l'islam, le tombeau du prophète Mahomet à Médine, était confié à d'anciens eunuques du Harem qui y servaient comme gardiens selon une coutume remontant au XII ${ }^{\mathrm{e}}$ siècle. À partir de la fin du XVII ${ }^{\mathrm{e}}$ siècle, ce devint l'habitude qu'un ancien chef des eunuques du Harem précédemment exilé au Caire fût nommé chef des eunuques de la Tombe (şeyhü-l-harem) à Médine. Le chef des eunuques de la Tombe servait de modèle de bonne conduite musulmane, tout en exerçant une autorité locale en tant que notable médinois.

\section{La fin : exécutions et tombes d'eunuques; fin de l'Empire et fin des eunuques du Harem}

Le dernier exposé fut consacré à la façon dont les chefs des eunuques du Harem firent face à leur fin, au sens large : il s'agit de la fin de leurs vies, mais aussi de celle de l'Empire ottoman, qui entraîna la disparition de la culture des eunuques du Harem.

Une étude des tombes des chefs des eunuques (localisation, taille, ornementation, inscriptions) fournit des clefs pour comprendre quels souvenir ils voulaient laisser après la mort, ou du moins quel souvenir leurs proches souhaitaient qu'ils laissassent. La piété des eunuques et l'assimilation au prophète Mahomet constituent des thématiques particulièrement significatives à ce sujet.

Beaucoup de chefs des eunuques moururent en exil en Égypte, et un tout petit nombre en poste, mais quelques uns furent exécutés, en particulier au XVIII ${ }^{\mathrm{e}}$ siècle. L'analyse des raisons de ces exécutions permet de repérer les marges de manœuvre politiques du chef des eunuques et la façon dont ces limites étaient définies.

Dans les dernières années de l'Empire ottoman, la position des eunuques du Harem connut des changements fondamentaux. À la suite des réformes des Tanzimat, le costume et le protocole des eunuques palatiaux de haut rang, comme ceux des sultans et de leur famille, se modernisèrent et s'européanisèrent pour une large part. L'effondrement de l'Empire ottoman après la première guerre mondiale entraîna la dispersion du Harem du Palais et la plupart des eunuques qui restaient tentèrent de s'adapter à la vie civile, avec plus ou moins de bonheur. Dans le même temps, à Médine, le gouvernement saoudien, qui s'était emparé de la ville dans les années 1920, supprima la garde d'eunuques de la tombe du Prophète et versa une pension aux derniers eunuques de la Tombe. 